\title{
Para um conceito moderno de imaginação: imaginação do ponto de vista kantiano
}

\author{
Towards a modern concept of imagination: imagination from the \\ Kantian perspective
}

\author{
Eugenia Gay \\ eugeniagay@hotmail.com \\ Doctora investigadora \\ Universidad Nacional de Quilmes \\ Malabia 1907/2D \\ 1414 - Buenos Aires \\ Argentina
}

\begin{abstract}
Resumo
Este trabalho apresenta uma avaliação crítica da discussão na qual foi produzido o conceito kantiano de "imaginação", como proposta de conhecimento e como projeto político-pedagógico. A hipótese sustentada é a de que a divisão da produção filosófica de Immanuel Kant e dos filósofos que participaram da discussão entre escritos teóricos e escritos políticos prejudica a compreensão do debate, resultando em uma concepção unilateral e oposicional do conceito moderno de imaginação. Para mostrar a unidade do debate, o artigo se concentra nos argumentos filosóficos desenvolvidos por Kant nos escritos pré-críticos e nas duas edições da Crítica da razão pura, contrastando-os com o conjunto da discussão da sua época. Embora os trabalhos de outros filósofos recebam menos atenção, o artigo espera tornar visível o caráter dialógico do trabalho teórico de Kant.
\end{abstract}

\section{Palavras-chave}

Imaginação; Ciência moderna; Immanuel Kant.

\begin{abstract}
This article makes a critical evaluation of the debate in which the Kantian concept of imagination was built as an epistemological, as well as a political-pedagogical project. The article's main hypothesis is that the distinction between political and theoretical writings in Immanuel Kant's works, as well as in the works of other philosophers who participated in this discussion, distorts the comprehension of the debate itself and produces a one-sided and oppositional conception of the modern concept of imagination. To show the unity of the debate, the article concentrates in the philosophical arguments developed by Kant in his pre-critical works and in both editions of the Critique of pure reason, which are presented vis-à-vis the broader debate of his time. Although the works of other philosophers do not receive the same attention as Kant's works, the article expects to expose the dialogical nature of Kant's theoretical oeuvre.
\end{abstract}

Keywords

Imagination; Modern science; Immanuel Kant.

Recebido em: 1/8/2014

Aprovado em: 15/1/2015 
Die an sich pöbel ist, weil sie nicht denk (KANT 1833, p. 30).

Die reine anschauung muß daher in gewisser Weise 'schöpferisch' sein (HEIDEGGER 1991, p. 44).

O pensamento de Kant sobre a imaginação constitui um divisor de águas na concepção moderna do conhecimento, mas ele não constitui uma unidade. Ao contrário, ele sofreu bastantes mudanças, que estão em parte relacionadas ao progresso intrínseco ao seu próprio desenvolvimento intelectual, e em parte à discussão que Kant manteve com partidários das doutrinas de G. Leibniz, Ch. Wolff, J. Locke e D. Hume, J. G. Hamman, e inclusive da sua própria, como J. G. Herder ou J.C.F. Schiller. Também é preciso lembrar que, mais do que propostas puramente "teóricas" ou metafísicas, destinadas a responder a um puro interesse de conhecimento, todas essas teorias constituíram tentativas de explicação sobre o mundo que compunham projetos morais, religiosos e políticos e, na maioria dos casos, normativos e práticos, associados a fortes alianças políticas e religiosas.

Este percurso pretende mostrar as transformações do conceito e funções da imaginação que se registram entre os escritos pré-críticos (escritos anteriores a 1770, data em que se estima o início dos trabalhos sobre a Crítica da Razão Pura) e a primeira edição da Crítica, por um lado, e a segunda edição da Crítica, por outro, como resposta à necessidade de defesa de uma variante do projeto Ilustrado, cujo sucesso parecia ameaçado pela vertente entusiasta ou perspectivista da filosofia. Dessa forma, a discussão kantiana sobre o papel da imaginação no conhecimento estabeleceu uma oposição taxativa entre a percepção ficcional e subjetiva e o conhecimento científico objetivo, base do projeto ilustrado da razão e ainda em vigência.

\section{Nenhuma ilha é uma ilha}

Em primeiro lugar, devemos considerar a importância, para o conjunto do projeto kantiano, das discussões que se desenvolviam na Inglaterra. De fato, muitos especialistas consideram que a passagem da filosofia "pré-crítica" ao projeto crítico tem a ver com uma mudança das lealdades filosóficas de Kant em direção à teoria newtoniana (BERLIN 1999, p. 23, passim). O pensamento de Newton penetrou no universo alemão na época de Frederico II, através da influência de Voltaire e de Maupertuis na Academia de Berlim (CALINGER 1969, p. 319), servindo como contraponto à posição filosófica wolffiana, que se manteve por algum tempo fora da Academia, resguardada na Universidade de Halle (RUPERT HALL 2002, p. 3-8). Embora a disputa entre Leibniz e Newton tenha se centrado principalmente no problema do cálculo, a inimizade entre os partidários de um e outro continuou depois da morte de ambos e se expandiu à totalidade dos dois sistemas filosóficos (RUPERT HALL 2002, p. 235).

A filosofia de David Hume, por sua vez, recebeu diferentes respostas, que podemos separar, para o período que vai de 1760 a 1785, em quatro grupos. Encontra-se, em primeiro lugar, a aceitação do seu ceticismo e a descrença 
em qualquer possibilidade de conhecimento. Alguns epistemólogos procuraram responder a Hume, como o fez Johan Nicolau Tetens. Em terceiro lugar, Hume foi interpretado como um defensor dos direitos da Fé contra a razão (Lavater, Hamann, Jacobi, Wizenmman, Herder) e, finalmente, a resposta de Kant, que generalizou o problema de Hume, forçando um reexame de toda a filosofia de Leibniz-Wolff.

Apesar da autoridade que Wolff ainda mantinha, para a década de 1740, ano da entrada de Immanuel Kant na Universidade de Königsberg, a sua filosofia vinha sendo alvo de duras críticas. Na prática, os professores mais destacados nas universidades alemãs usavam a filosofia wolffiana como base das suas reflexões, mas corrigiam as suas conclusões mediante a aplicação das investigações de Newton (CALINGER 1979, p. 349), Locke ou Hume (KUEHN 2001, p. 68, p. 75).

Desde o início da sua carreira, Kant interessou-se pelo problema da conformação e da percepção da realidade e, com o avanço dos seus estudos, foi desafiando uma por uma todas as metafisicas disponíveis. Nos seus trabalhos mais relacionados à filosofia natural, Kant chegou a considerar que a ciência newtoniana era mais avançada do que aquela proposta por Wolff (CALINGER 1979 , p. 353-355, passim), embora na sua proposta geral continuasse aderindo mais à teoria monádica da matéria (KUEHN 2001, p. 90-110), e no seu Principiorum primorum cognitionis metaphysicae nova dilucidatio (1755), desafiou diretamente os princípios de contradição e de razão suficiente. Essa mudança aponta para um redirecionamento de perspectiva a favor de um ponto de vista mais próximo ao de Newton (SCHÖNFELD 2000, p. 58). As teorias sobre o tempo e o espaço, que Kant começou a desenvolver na sua Dissertação inaugural de 1770, têm sido entendidas como um dentre os vários esforços de mediação entre as concepções newtoniana - de caráter absoluto - e leibniziana - relacional - do tempo e do espaço (BALLARD 1960).

Cabe lembrar, contudo, que para Leibniz as mônadas funcionavam como centros espirituais incorpóreos, e não tinham a existência material que Wolff Ihes havia atribuído (LEIBNIZ 2008, p. 26). De qualquer maneira, a "redescoberta" de Leibniz que seguiu à publicação das suas obras originais, não significa que Kant tivesse operado alguma espécie de "volta a Leibniz" que obliterasse as interpretações de Wolff. Muito pelo contrário, os trabalhos pré-críticos de Kant sobre a imaginação foram particularmente influenciados pela discussão em torno da tradição wolffiana.

De Alexander G. Baumgarten, considerado o mais importante dentre os seguidores de Wolff, Kant aproveitou a discussão sobre a capacidade da imaginação para perceber uma totalidade de um só golpe, assim como a associação dessa percepção da totalidade com o atributo da beleza (MAKKREEL 1990, p. 10). Na Metafísica (BAUMGARTEN 1988, §607), Baumgarten também havia se dedicado à discussão sobre a faculdade do juízo, identificada como a responsável pela formação do gosto. Os escritos pré-críticos de Kant em geral são considerados mais próximos de Baumgarten do que do trabalho de Wolff, na medida em que o primeiro também havia recuperado os trabalhos de Leibniz diretamente (KUEHN 
2001, p. 91-92). E a marca de Baumgarten, junto com a de Moses Mendelssohn, se torna extremamente importante considerando que Kant tinha dificuldades com a língua inglesa, de forma que o seu acesso aos textos ingleses se fez a través dos trabalhos desses filósofos. Baumgarten aparece como uma influência ainda maior se considerarmos a sua posição contrária ao movimento da filosofia popular e ao mero Schöndenker: se Baumgarten pretendia fundar uma ciência do belo, essa ciência respondia ao conceito wolffiano de rigorosidade, e não ao sentimentalismo dos populares. Esse direcionamento foi retomado por Kant (ZAMMITO 2002, p. 39).

O interesse de Kant pela imaginação se desenvolveu bastante cedo, durante os anos de 1760. John Zammito explica que "desde o início, Kant concebeu a imaginação estética como a perigosa capacidade de projetar o irreal sobre o efetivamente existente" (ZAMMITO 1992, p. 33). Zammito cita uma passagem de meados da década de 1760 na qual Kant afirma: "De fato, a imaginação [Einbildung] consiste na ilusão [Täuschung] segundo a qual acreditamos ver alguma coisa no objeto que é, na realidade, uma criação do nosso próprio cérebro. Dessa maneira os entusiastas [Schwärmer] passam a acreditar que podem encontrar todos seus espectros [Hirngespinsten], e qualquer seita os seus dogmas, na Bíblia". E de fato, não é por acaso que, junto à discussão sobre a imaginação nas suas lições de antropologia, encontra-se também a análise psicológica das doenças mentais. A imaginação era, em última instância, algo que devia ser devidamente controlado, e cujo descaso ou excesso se encontrava tanto no empirismo ceticista dos ingleses quanto na base do dogmatismo metafísico. E pior ainda, a imaginação descontrolada se encontrava em atitudes como a de Johann G. Hamman, aquele "completo caos de materialismo e espiritualismo, de luz e sombras", no dizer de Jacobi (HILLEBRAND 1872, p. 114), uma louvação ao irracionalismo na própria universidade de Königsberg.

\section{A antropologia do ponto de vista imaginário}

Apesar do perigo, Kant entendia que não era possível prescindir totalmente da imaginação. No seu Anthropologie, Kant explicará o funcionamento da Bildungsvermögen, ou "poder formativo", em todo tipo de formação produzida pelas faculdades inferiores, isto é, na apreensão sensorial. O texto da Antropologia é de especial importância porque, embora fosse publicado em 1798 , ele é o fruto dos cursos de antropologia que Kant começou a ditar em 1772, e que acompanharam o desenvolvimento da Crítica.

Nesse texto, Kant sustenta que o poder formativo não somente possibilita formar imagens (Bild), mas também combinar representações em geral, seja mediante coordenação, no caso dos objetos sensíveis (Bildungskraft), ou a través da subordinação, para os objetos racionais (Einbildung). Esta última, a subordinação, muitas vezes funciona inconscientemente. Assim mesmo, Kant entende que "as representações a respeito das quais a mente se conduz passivamente, ou seja, pelas quais o sujeito é afetado (que pode se afetar a si mesmo ou ser afetado por um objeto), pertencem à faculdade do conhecimento sensível, enquanto aquelas que encerram somente um fazer (o pensar) pertencem 
à do conhecimento intelectual" (KANT 1833, p. 24). As primeiras também são chamadas inferiores e plebeias, como se lê na epígrafe desse texto, posto que não pensam - nem julgam (KANT 1833, p. 33), enquanto as segundas são superiores. O tipo de sensibilidade que compete ao conhecimento compõe-se dos sentidos e da imaginação (facultas imaginandi), esta última definida como a intuição em ausência do objeto. Ela pode ser produtiva (exhibitio originaria), quando apresenta um objeto originalmente, ou reprodutiva (exhibitio derivativa), quando traz à mente uma intuição empírica passada: "As intuições puras de tempo e espaço pertencem à faculdade produtiva, todas as outras pressupõem intuição empírica, que passamos a chamar experiência quando é conectada com o conceito do objeto e se transforma assim em conhecimento empírico". A produção involuntária de imagens, por sua vez, é chamada de fantasia (KANT 1833, §13; p. 26).

Mas Kant destaca claramente que, embora possa apresentar imagens originais, a imaginação nunca cria, pois sempre é possível encontrar a origem das imagens que a imaginação produz nos sentidos (KANT 1833, §30). Desta capacidade da imaginação de produzir analogias entre as percepções reais e as suas produções fictícias, provêm expressões como "sem sentido", ou "sentido comum", nas quais se expressa a relação entre a base sensorial e o trabalho da imaginação que é necessária para o conhecimento. De forma que a faculdade de produção da sã imaginação se entende, pelo menos nos primeiros anos, como uma capacidade combinatória, e não poiética.

Nesse mesmo texto, Kant separa aquelas produções originais da imaginação que concordam com conceitos, e que são consideradas como expressões do gênio, do simples delírio, que não concorda com conceitos (KANT 1833, §28). Ainda dentro da imaginação produtiva, distinguem-se três classes de imaginação: a primeira é plástica (imaginatio plástica), da intuição no espaço, a segunda é associativa (imaginatio associans), da intuição no tempo, e a terceira é aquela da afinidade (affinitas), das representações de descendência comum. Quando a imaginação plástica é utilizada conscientemente pelo artista, chama-se composição, caso a sua atuação seja inconsciente, é qualificada como uma monstruosidade ou como sonho. Ao contrário, a imaginação associativa (imaginatio associans) muitas vezes não responde à vontade do sujeito, e parece descrever o fenômeno do qual também falava Hume, segundo o qual a mente forma "cadeias" ou "trens" de pensamento, associando uma representação à outra e atribuindo- Ihes causalidade. A associação (imaginatio associans) também é responsável pela predição do futuro e pela memória. A primeira destas capacidades, que consiste na projeção de possibilidades ao futuro, repousa na aplicação da lei da causalidade, sempre que não se trate somente de um pressentimento, e a segunda, que supõe a organização das imagens do passado, consiste na aplicação do entendimento. A terceira classe de imaginação (affinitas) pode muito facilmente vagar de um assunto a outro, pois segue a forma da percepção do sentido mais do que a lei do entendimento, criando muitas vezes pura confusão. 
Dentro das atribuições da imaginação se conta, também, a faculdade de designar (Bezeichnungvermögen ou facultas signatrix), cujo grau mais elevado é o da distinção, em que se especifica que "o conhecimento simbólico tampouco se opõe, pois, ao intuitivo (por intuição sensível), mas antes ao intelectual (por conceitos)" (KANT 1833, p. 104), de forma que o conhecimento simbólico pertence muito mais à sensibilidade do que ao entendimento. Embora se apresente como análogo, e com isso sugira a igualdade de condições, ou pelo menos de procedimentos, a descrição kantiana da analogia apresenta sempre uma ponderação quanto ao valor relativo de cada classe de conhecimento. Assim como a imaginação é a responsável pela comunicação entre as faculdades, e o seu caráter antropológico garante a universalidade dos juízos do entendimento, ela também é o lugar onde se distingue entre conhecimentos racionais e não racionais. Contudo, apesar de ser imprescindível para ela, a imaginação não pertence à faculdade superior, que é mais eminente, composta por "um entendimento justo, um juízo exercitado e uma razão profunda" (KANT 1833, §40). Embora participe da tarefa do entendimento, a imaginação pré-crítica permanece no campo da sensibilidade, ou seja, pertence às faculdades inferiores que lidam com os objetos do mundo exterior (KANT 1997, p. 48).

Nas transcrições das Lições de metafísica que Kant ditou entre 1778 e 1779, o cenário que havia sido descrito na antropologia adquire maior complexidade, mediante a separação e limitação das funções que pertencem aos sentidos e as que pertencem ao entendimento: os sentidos providenciam a matéria e o estofo 80 do conhecimento, que é complementado pela espontaneidade do entendimento, que proporciona forma à percepção (KANT 1997, p. 51). Na sequência, Kant passa a definir uma classe de conceitos produzidos pelo entendimento cuja origem não é diretamente sensorial, mas que outorga forma às cognições sensoriais. Trata-se de conceitos intelectuais, que o entendimento produz ao refletir espontaneamente sobre a experiência. Esses conceitos são o produto de juízos de reflexão, e não a representação direta da experiência, embora tal distinção se torne imperceptível pelo hábito de realizar uma mesma operação uma e outra vez. Apesar da sua complementariedade, Kant entende que as impressões devem distinguir-se dos juízos, pois acredita que as ilusões (os "enganos") atribuídas erroneamente aos sentidos (como o fez Descartes), assim como o impulso do entendimento de corrigi-las formando, mediante esse processo, os seus próprios conceitos, são somente a consequência de juízos precipitados. Na produção dos conceitos sensíveis intelectuais vemos a atuação formadora da imaginação, no escopo do entendimento, que é a faculdade superior ou intelectual. Nesses trabalhos, a imaginação participa de uma concepção que poderíamos chamar pictórica, como a que já haviam sustentado os neoplatonistas e os pensadores cristãos.

De maneira que, por um lado, existe uma cognição de objetos particulares por assim dizer imediata, nomeadamente, aquela que é dada aos sentidos ao serem afetados pelos objetos imediatamente presentes, e cujo produto é chamado representação dos sentidos. Por outro lado, existe uma cognição imitativa que se realiza através do poder ( $k r a f t$ ) formativo, procedente da espontaneidade do 
entendimento. As impressões produzidas pelo poder formativo em ausência do objeto tampouco devem confundir-se com as impressões que provém diretamente dos objetos (KANT 1997, p. 52), como talvez o tenham feito Locke ou Hume, que Ihes atribuíram um nível equivalente de vivacidade. Em outras palavras, o poder formativo decorrente da espontaneidade da mente produz representações sensíveis do passado, do presente ou do futuro em ausência do objeto, mas que possuem em si mesmas a forma em que os objetos afetariam os sentidos e que por isso representam o perigo de confundir a forma com a coisa em si.

O poder formativo se divide, por sua vez, em três poderes ou faculdades temporais e três intemporais (KANT 1997, p. 53). Dentro dos poderes temporais encontramos a faculdade de Ilustração (facultas formandi, ou Abbildung), cujas representações correspondem ao presente, a faculdade da Imitação (facultas imaginandi ou Nachbildung), que providencia as representações do passado e, finalmente, a faculdade da Antecipação (facultas praevidendi ou Vorbildung), cujas representações pertencem ao futuro.

Dentre as três faculdades temporais, a Abbildung parece desenvolver o papel mais importante, na medida em que concentra a capacidade de unificar as imagens que se apresentam aos sentidos, assim como seus limites, sempre que não nos vejamos ultrapassados pelas nossas impressões. Na terceira Crítica, a impossibilidade de estabelecer limites para a percepção será descrita como a experiência do sublime, passando a conformar uma estrutura diferente daquela do conhecimento e apontando a sua última fronteira. Apesar da sua distinção inicial, a Abbildung não se limita à ilustração da imagem presente. Ela envolve no seu escopo também os outros dois tipos de imaginação temporal, operando em forma de associação empírica. Por um lado, a Abbildung combina imagens que tinham sido previamente "guardadas" em uma espécie de armazém ou depósito da imaginação. Essas imagens passadas, ou já ausentes, são trazidas ao presente (à presença) pela Nachbildung, ou imaginação reprodutiva, através do mecanismo da associação. Pela mesma arte, denominada Vorbildung, as nossas representações presentes são também associadas a representações futuras. Todos os tempos imaginários se combinam na presença imediata que Kant denomina Abbildung.

Dentro das capacidades intemporais do poder formativo, há que contar a Faculdade da imaginação (Einbildung), também chamada imaginação produtiva, ou faculdade da fantasia, pela qual somos capazes de criar imagens originais, no sentido platônico. Ela é diferente e não deve ser confundida com a imaginação reprodutiva (temporal) que participa da formação representacional, pois as suas representações independem da existência real dos objetos (KANT 1997, p. 55). Para Kant, a faculdade da imaginação é um poder ficcional dos sentidos, que também se diferencia do poder ficcional do entendimento (Einbildungsvermögen). O sentido de "fictício" nesse caso designa a ausência de correlação atual no mundo para a imagem produzida na mente, da mesma forma como acontecia no trabalho de Christian Wolff, e com isso distingue esta faculdade fictiva daquele outro sentido de cópia especular da realidade que caracterizava a imaginação reprodutiva. A segunda das capacidades 
intemporais da imaginação é a faculdade de correlação (facultas characteristica ou Gegenbildung), que nos permite formar analogias linguísticas, na medida em que possibilita a produção de signos. Esta faculdade, de cunho sensível, parece acompanhar a Bezeichnungvermögen ou facultas signatrix que havia já sido introduzida na Antropologia. Finalmente, distingue-se a faculdade de cultivo, ou cultura (Ausbildung), que possibilita e nos compele a completar, espontaneamente, as imagens que possam se apresentar aos sentidos somente de maneira parcial.

Na medida em que estes "atos" acontecem de maneira involuntária, eles são governados pela sensibilidade ou faculdade inferior; enquanto se realizam de maneira voluntária, correspondem ao domínio do entendimento ou faculdade superior. Por esse motivo, embora a rigor pertençam aos sentidos, Kant também conta a memória (a imaginação reprodutiva) e a faculdade imaginativa voluntária (Dichtkunstvermögen) como atos do entendimento. Dessa forma, as faculdades cognitivas superior e inferior continuam a se diferenciar segundo a relação da intuição com os objetos (KANT 1997, p. 250).

Em resumidas contas, a faculdade da imaginação pode ser reprodutiva, quando se refere ao tempo passado e responde às leis de associação. Nesse caso, também pode atuar de forma voluntária ou involuntária. Pode ser antecipatória, quando se refere ao futuro e responde à lei de antecipação de resultados similares. Finalmente, pode ser produtiva, quando não se refere a tempo ou objeto algum e responde somente à lei da compatibilidade. Uma última especificação sobre a 82 facultas fingendi (que temos traduzido como "fictiva") é a que se realiza mais adiante nas Lições e que distingue entre a imaginação, quando denomina o ato de jogar com a imaginação para fabricar alguma coisa com um propósito ou um fim, e a fantasia, que implica que é a imaginação quem joga conosco. A fantasia que não está dirigida pela analogia com a experiência e pela faculdade superior provoca um frenesi incontrolável e, no limite, a loucura (KANT 1997, p. 254). É difícil subestimar a importância que cobra, na medida em que o texto avança, a distinção entre as atividades conscientes e as atividades inconscientes. Em todas as oportunidades, a consciência de uma ação determina o seu pertencimento à faculdade inferior ou à faculdade inferior. Dessas considerações surge também um conceito de beleza associado à vontade e ao prazer, que também é subdividido em uma versão consciente e outra inconsciente, e aqui a conversa parece ter lugar com as considerações de Moses Mendelssohn (MENDELSSOHN 1819, p. 102). O objeto capaz de causar prazer objetivo está ou em acordo com as leis da sensibilidade, e nesse caso é considerado belo, ou em acordo com as leis do entendimento e da razão e, nesse caso, ele é bom. A premissa nessa distinção é que a sensação se relaciona com o material, enquanto que o gosto diz respeito à forma que adquire a composição do múltiplo na sensação (KANT 1997, p. 260).

Parece evidente que no tempo em que essas segundas lições foram ditadas, se encontrava já em circulação um trabalho que modificava amplamente as atribuições e funções da imaginação. Antes de 1781, data da primeira publicação da Crítica da razão pura, a imaginação possuía diversas funções e permeava todo o trabalho da mente. De maneira muito similar ao funcionamento da 
faculdade única postulada por Ch. Wolff, a imaginação kantiana respondia ora às faculdades superiores, ora às faculdades inferiores, sem que lhe fosse conferido um lugar específico, ou seja, limitado, na economia da percepção. Alguns autores acreditam que os escritos pré-críticos representam uma tentativa falha de construir um sistema que unificasse a natureza e a metafísica. Outros acreditam que a falha foi consequência da incapacidade de Kant de se livrar do peso da tradição da metafísica para admitir a suficiência das faculdades inferiores. A culminação desse projeto foi, segundo Martin Schönfeld, a convicção de que tais mundos estavam definitivamente separados, a consequente inclinação pelo modelo newtoniano, mas tingido de racionalismo, e o início do projeto crítico (SCHÖNFELD 2000, p. 246).

\section{O Ser Imaginário}

A razão pela qual a imaginação se torna um problema na Crítica da Razão Pura (1781) é que o conhecimento transcendental que ela propõe somente é possível através da sua atividade. Martin Heidegger adota uma forma muito interessante, e discutida infinitas vezes, de definir o objetivo da Crítica, que nos conduz ao nó górdio da imaginação kantiana. Heidegger entende que a imaginação é a raiz comum, embora não reconhecida, às duas fontes possíveis do conhecimento: a imaginação designa o lugar do qual partem tanto a intuição sensível quanto a espontaneidade do entendimento. Heidegger re-enuncia o problema que articula a Crítica, isto é, a pergunta pela possibilidade dos juízos sintéticos a priori, da seguinte maneira: "Como pode um ser finito, que como tal é entregue (ausgeliefert) ao ente e dependente da sua recepção ter conhecimento de, isto é, intuir, o ente antes que ele seja dado sem ser o seu criador?" (HEIDEGGER 1991, p. 38). Com isso, o problema kantiano deixa de ser um problema de conhecimento (o de como é possível conhecer o mundo), para se tornar um problema ontológico, na mesma linha do trabalho do próprio Heidegger.

Até que ponto esta reformulação diz mais sobre os interesses do próprio Heidegger do que sobre a Crítica é outra discussão (Cf. BAMBACH 1995; CASSIRER 1931; SHEROVER 1971; WEATHERSTON 2002), mas ela aponta uma perspectiva importantíssima na concepção kantiana da imaginação. Será que apesar de fundar a epistemologia moderna, a Crítica não é ela mesma um trabalho de epistemologia propriamente dito, e sim de gnosiologia? A análise que Heidegger realiza do papel da imaginação na síntese de conhecimento se centra na primeira edição da Crítica da razão pura, e estabelece uma distinção a respeito da segunda edição. Segundo Heidegger, "embora a tendência toda da Crítica aponte à função central da imaginação no que respeita à possibilidade da síntese ontológica, Kant negou-se a reconhecê-lo e na segunda edição reduziu a imaginação a uma 'função do entendimento" (HEIDEGGER 1962, p. XIX). E de fato, as múltiplas funções que a imaginação tinha na primeira edição da Crítica, são transformadas em uma nova, porém muito delimitada, definição da sua atividade, que será denominada esquematismo transcendental, e que será submetida ao domínio do entendimento. 
Na Crítica (a), a imaginação é vista como um poder ( $K$ raft) capaz de produzir esquemas a priori. Esses esquemas a priori resultam da aplicação espontânea das categorias do entendimento à intuição pura. Essa aplicação possibilita o processamento da informação recebida através dos sentidos. Ou seja, sua função é a síntese que determina o sentido interno do tempo. Heidegger explica que "os esquemas 'surgem' como o produto transcendental da imaginação transcendental. Esta última, enquanto síntese original, pura, forma a unidade essencial da intuição pura (tempo) e do pensamento puro (apercepção)". (HEIDEGGER 1962, p. 134). Visto desde a perspectiva do seu resultado, Kant está nos dizendo que um conceito (ou uma categoria) é o produto da atividade sintética da imaginação, seja esta uma síntese empírica ou pura. Ou seja, é somente através da síntese da imaginação que as "marcas" ou dados isolados da intuição se transformam em partes de "algo", seja este "algo" um objeto sensível ou um objeto do entendimento (um conceito), que depois virá a dar forma à síntese da intuição pura (HEIDEGGER 1991, p. 64).

Ora, para que isto seja assim, Kant pressupõe primeiro que há alguma coisa "além" do fenômeno, denominado noúmeno. Segundo, que esse algo, o noúmeno, só é (se é) apreensível de maneira transcendental, isto é, não através da investigação exterior ou acidental do fenômeno, e sim descobrindo as formas a priori de apreensão desse mesmo fenômeno. O seja, para apreender o noúmeno, o que não significa que o conheçamos, é necessário transcender o plano dos fenômenos. Devemos lembrar que "a distinção entre o conceito de coisa em si e o de aparência não é objetiva, senão meramente subjetiva. A coisa em si mesma não é outro objeto, mas outro aspecto (respectus) da representação em relação ao mesmo objeto" (KANT apud HEIDEGGER 1991, p. 33). Consequentemente, esse objeto transcendental poderia se definir também como puro horizonte, de maneira que deve permanecer em estado de aberto para cumprir a sua função, embora não possa ser tematizado nem conhecido positivamente.

Por enquanto, sabemos que o conhecimento se realiza a partir ou através de duas vertentes (o entendimento e a intuição), que provém da mesma fonte, embora essa fonte seja desconhecida. Desconhecida para Kant, pois Heidegger entende que se trata claramente da imaginação. A unidade essencial do conhecimento, que de outra forma permaneceria ou no plano da intuição ou no plano do entendimento, se realiza no ato espontâneo da imaginação através do qual se abre o horizonte da possibilidade do objeto. Em termos mais kantianos, a imaginação realiza a priori a conexão dos conceitos puros do entendimento (as categorias) e a intuição pura (o tempo), explicando assim o seu caráter transcendental. A imaginação torna visível o espaço em sua forma pura através do esquema: "a sensibilização tem lugar como um esquematismo. A imaginação pura ao formar o esquema dá por adiantado o aspecto (imagem) do horizonte da transcendência" (HEIDEGGER 1991, p. 91). Ora, segundo esta interpretação, a imagem de um conceito não é uma imagem particular, e sim um conjunto não visual de regras que definem a imagem particular. Em outras palavras, não podemos contemplar o esquema em si, mas o percebemos toda vez que vemos uma imagem particular que pode ser subsumida sob um conceito. 
Novamente em palavras de Heidegger, "o conhecimento ontológico [que é o objetivo da crítica e aquilo explicitado na análise das categorias] tem provado ser aquele que forma a transcendência" (HEIDEGGER 1991, p. 120). Segundo esta interpretação, a imaginação abre o terreno do possível, em que os objetos da percepção podem ser intuídos, sem por isso constituir uma imagem ou um espaço físico determinado: providencia o como da percepção, mas não o que.

Na Primeira versão da Crítica se descrevem três classes de síntese subjetiva possíveis (KANT 1956, p. 141a). A primeira é aquela da apreensão intuitiva, pela qual a intuição mesma recolhe as representações, sejam empíricas ou internas, que são sempre múltiplas em função do seu pertencimento ao sentido interno (o tempo), e as reúne originalmente em uma unidade. A segunda consiste na reprodução imaginativa, mediante a qual a imaginação empírica (empirische Einbildungskraft) estabelece um laço entre as representações que amiúde se apresentam juntas, e assim, reproduz na representação essa ligação toda vez que observa a aparição de um dos fenômenos. Nesse apartado, Kant também explica que as sínteses da apreensão e a da reprodução se encontram intrinsecamente ligadas, constituindo o fundamento transcendental da possibilidade de todo conhecimento, empírico ou transcendental, pelo qual também recebem o nome de faculdade transcendental da imaginação (transzendentale Vermögen der Einbildungskraft). A terceira síntese é a do reconhecimento conceitual, isto é, a consciência (Bewußtsein) da concatenação ou unidade formal a priori dos pensamentos que se apresentam de maneira sucessiva através da apercepção transcendental que, pela síntese, compõe o objeto transcendental, isto é, a realidade objetiva (KANT 1956, p. 158-159a). Essas três sínteses foram entendidas por Heidegger como sendo, respectivamente, o correlato da Abbildung, da Nachbildung e da Vorbildung que já havíamos identificado nas Lições de Metafísica. Segundo a Crítica, todas elas, aliás, pertencem à temporalidade. A imaginação transcendental transformar-se-ia, dessa forma, no tempo primordial e, portanto, na raiz comum entre o sentido e o entendimento.

A terceira síntese, a do reconhecimento conceitual, tem duas funções. A primeira é o reconhecimento da identidade de dois pensamentos correlatos, sem a qual não conseguiríamos mais do que ter novas representações a cada momento, caindo assim na alternativa proposta por Hume. A segunda função produz uma unidade que permite o reconhecimento de uma totalidade. Heidegger relaciona essa função à Vorbildung que, nos escritos pré-críticos, era antecipatória. Resulta evidente que Heidegger tem em mente a função antecipatória de sentido compreendida na noção de círculo hermenêutico que fora elaborada em Ser e tempo. Lida nessa perspectiva, a síntese conceitual parece sim ter essa "função" antecipatória, na medida em que projeta uma expectativa de sentido total que permite outorgar também um sentido às partes.

Contudo, fica evidente que a função do reconhecimento na Crítica se relaciona diretamente com a passagem do plano fenomênico ao plano nouménico ou metafísico, no qual Kant pode fundar a objetividade do conhecimento a partir do objeto transcendental. Dessa forma, podemos chamar a atenção sobre o fato de que a possibilidade da objetividade do conhecimento ou, mais precisamente, 
a realidade objetiva enquanto tal, se conforma a partir de um objeto imaginário, ou seja, um objeto constituído na passagem ao plano transcendental realizada mediante o trabalho da imaginação. Esta interpretação se justifica se pensarmos que, quando o conhecimento retorna ao plano fenomênico, ele deve sair do território do objeto transcendental, pois um esquema ou um conceito, por definição, nunca podem coincidir com uma representação determinada da sensibilidade. A objetividade, portanto, somente se sustenta no plano transcendental, cujo propileu é a própria esquematização imaginária. Mas se esta interpretação parece insana, isso se deve a que a concepção da imaginação, e consequentemente a definição do conhecimento, iria sofrer ainda uma importante transformação, depois da qual objetividade e ficção não poderiam sequer ser colocadas na mesma frase sem produzir estranhamento.

Heidegger entende que Kant recuou da sua posição em relação à função central da imaginação por ocasião da segunda edição da primeira Crítica (HEIDEGGER 1991 , p. 160-161). E de fato as passagens que na primeira edição definiam a imaginação como terceira faculdade são substituídas por discussões dirigidas a refutar a validade do baseamento empírico (ou empirista) do conhecimento no pensamento de Hume e de Locke (KANT 1956, p. 135), com o que a função da imaginação é ali notavelmente restrita. $\mathrm{E}$, aliás, com toda coerência, pelo mesmo movimento em que a imaginação é desbancada da sua posição central, Kant questiona a legitimidade das faculdades sensíveis ou inferiores. O esquematismo transcendental baseado na síntese da imaginação, que, na primeira edição ocupava o primeiro plano na explicação sobre a possibilidade do conhecimento transcendental, cede a sua posição central ao juízo, cuja validade se sustenta na unidade da apercepção. Nessa segunda versão, Kant passa de um esquema tripartite, composto pela intuição sensível, a imaginação e a apercepção, para um esquema duplo, composto de intuição sensível e entendimento, enquanto a imaginação, que na primeira versão ficava "desabrigada" (heimatlos) (HEIDEGGER 1991, p. 136), passa a compor uma das operações do entendimento.

\section{Fronteiras imaginárias}

É lícito pensar que para a segunda edição da Crítica da razão pura, e depois de várias discussões e controvérsias, Kant estava disposto a conceder menos a leibnizianos e empiristas. O novo texto pretendia escapar tanto à crítica do idealismo excessivo em sua teoria como à interpretação do seu trabalho como um manifesto empirista. Para isso, Kant introduziu mudanças significativas, que esclareceriam a originalidade da sua doutrina. No estudo preliminar à edição brasileira da Crítica da Razão Pura, nota-se que

são ampliadas a introdução e algumas passagens da "estética transcendental". Refunde-se totalmente a dedução dos conceitos puros do entendimento e, parcialmente, o capítulo "Da distinção de todos os objectos em geral em fenômenos e noúmenos". Na "Analítica dos princípios" acrescenta-se a "Refutação do idealismo" e a "Observação geral sobre o sistema dos princípios". É refundido e encurtado o capítulo relativo aos "Paralogismos da razão pura" (MORUJÃO apud KANT 2001, p. III). 
E essas mudanças não são acidentais. Em 1787, seis anos depois da publicação da primeira edição, Kant se encontrava muito mais afastado da filosofia de Leibniz-Wolff, assim como dos seus próprios "seguidores". Entre ambas as edições, Kant havia se engajado em múltiplas discussões com o objetivo de defender e impulsionar a sua teoria. Para começar, os comentários que seguiram à publicação da Crítica não foram nem muito numerosas, nem das mais elogiosas, e em geral identificaram o trabalho de Kant entre os partidários de uma ou outra tradição filosófica sem reconhecer, a juízo de Kant, a sua verdadeira importância e originalidade (KUEHN apud GUYER 2006, p. 640). Kant entendia que o conceito e a possibilidade da razão pura deviam ser defendidos contra os seus inimigos. E mais ainda, chegou até a responsabilizar o seu antigo aluno J.G. Herder (1744-1803) pela pobre recepção do livro.

E talvez com alguma razão. Para os filósofos do Sturm und Drang, a ideia de um conhecimento alcançado através de uma razão pura, sem mediação da linguagem por meio da qual apre(e)ndemos a nossa cultura e história particulares, era simplesmente impossível. Em um escrito de 1778, Herder criticava a possibilidade de distinguir perfeitamente entre as diferentes cognições da alma argumentando que, embora as sensações pudessem ser atribuídas particularmente a cada um dos sentidos para fins classificatórios, uma vez coletados, todos os estímulos externos se combinam no interior do homem, mediante a imaginação (Einbildung), sem que se possa apontar entre eles um responsável "puro" pela percepção (HERDER 2002, p. 204). Em oposição às formas puras da espontaneidade que Kant defendia como a faculdade humana que torna possível o conhecimento, Herder postulava o conceito da Reflexividade (Besonnenheit ou Besinnung), que consiste em um perpétuo melhoramento ou refinamento de si próprio entendido como um fim em si mesmo. O mecanismo reflexivo (HERDER 2002, p. 83) se descreve como uma vontade total, como um sentido ou uma direção, mais do que um conjunto de faculdades discretas que pudessem ser combinadas segundo as necessidades ou como unidade dada da apercepção. Dada esta totalidade direcional da reflexividade, uma faculdade que realize a transição entre o mundo físico e o mundo dos conceitos puros do entendimento ou da moral, como a imaginação faz na teoria kantiana, acaba se tornando supérflua ou, talvez, impossível de distinguir. Portanto, no conceito de conhecimento como formação apresentado por Herder, a imaginação deixa o seu lugar como faculdade constitutiva do entendimento, para o sujeito como totalidade direcional, que se torna o formador do mundo e de si próprio, atualizando-se sucessivamente a cada nova experiência. Se na Crítica da razão pura a correspondência entre o sujeito e o mundo está dada espontaneamente e de antemão, para o que ela precisa estar já totalmente formada, disposta e oposta, na proposta de Herder essa correspondência é fundamentalmente histórica e se expressa na linguagem (SIKKA 2007, p. 48).

A insatisfação de Kant no que diz respeito aos rumos tomados por Herder ficam bem expressados na sua resenha do Ideias para uma filosofia da história da humanidade, que Herder publicou em 1784. No texto, aparecido em janeiro de 1785 , Kant julga que Herder ainda devia aprender a moderar a imaginação 
que, "seja metafisica ou sentimental" não leva a lugar nenhum (KUEHN apud GUYER 2006, p. 651). Na resenha da segunda parte do texto de Herder, publicada em março de 1785, Kant repreendeu novamente a ausência de limites entre as linguagens filosófica e poética, respondendo à intervenção que K. L. Reinhold havia realizado em favor de Herder. Kant ponderava "se com frequência o manto de metáforas ousadas, imagens poéticas e alusões mitológicas não acaba ocultando o corpus de pensamento como uma névoa, ao invés de deixálo brilhar placidamente como sob um véu translúcido" (KANT 2006, p. 138). As posições assumiam formas cada vez mais contrapostas, como se observa na purificação epistemológica realizada na segunda edição da Crítica, em 1787.

Uma crítica similar à morfologia da relação entre o mundo e o sujeito defendida por Kant havia sido realizada por J. G. Hamann (1730-1788) em uma Metacrítica que seguiu logo depois da aparição da primeira edição da Crítica da Razão Pura (KUEHN apud GUYER 2006, p. 633). Nesse escrito, Hamman criticava tanto a ignorância da linguagem natural enquanto baseamento de todo pensamento, quanto a separação artificial de pensamento e sensibilidade. A dicotomia entre a forma do pensamento e o conteúdo da experiência resultava não somente enganosa, na medida em que sobrevalorava um aspecto formal formalizador subjetivo, que acabava predeterminando a experiência, mas, principalmente, uma dicotomia desta classe era efetivamente insustentável (ALEXANDER 1966, p. 139).

Porém, se bem é verdade que os filósofos do Sturm und drang 88 representavam uma alternativa ao projeto ilustrado de Kant, eles não se opunham necessariamente à produção de um sistema de conhecimento comprovável e controlável. Antes bem, a discrepância parece encontrar-se na concepção de individualidade "livre" que se descobre implícita nesse tipo de conhecimento, e na oposição da racionalidade "pura" à experiência. O projeto de Kant supunha que a liberdade individual deveria ser fundada a partir da sujeição à norma de uma razão atemporal, pura, quase sagrada, cujo cumprimento constituía um fim em si mesmo. Ao contrário deste imperativo puro da razão, a individualidade pregada pelo Sturm und Drang procedia da particularidade do que é histórico e mundano, uma individualidade formada e envelhecida, "ganha", por assim dizer. O individuo do Sturm und Drang é um sujeito liberado da regra divina por própria vontade, por arte própria, e que tem sofrido profundamente o desamparo dessa autonomia tanto quanto a sua libertação. Ele representa, como Prometeu (GOETHE 1998), a autoridade criativa do indivíduo no mundo que ele próprio cria. Com essa nova individualidade, a imaginação perde a sua identidade como unidade discreta dentro da maquinaria do entendimento. De alguma forma, ela volta à unidade da alma (da psykhé) como totalidade criativa direcionada.

Apesar da sua inicial desconsideração ou subavaliação, em 1784 apareceu uma primeira defesa da Crítica desenvolvida por Johann Schulz, não sem o estímulo do próprio Kant. Na sequência, em 1786, o Deutscher Merkur começou a publicação das Cartas sobre a filosofia de Kant de K. L. Reinhold, que multiplicaram notavelmente o espectro da recepção da Crítica. Com a crescente repercussão do seu trabalho, e com o esforço continuado para se posicionar nos 
debates da época, Kant se transformava em um dos filósofos mais importantes da cena alemã (KUEHN apud GUYER 2006, p. 657). As décadas de 1770 e 1780 viram o apogeu do movimento do Sturm und Drang, e o início do movimento romântico, que se veria materializado na década seguinte. Embora em certa forma o Romantismo tenha se apropriado de Kant, este último entendia que o movimento de Tempestade e ímpeto se propunha a si próprio como o inimigo do Iluminismo. Nesse sentido, Kant se dispôs a fazer a defesa não do racionalismo iluminista e do projeto pedagógico da Ilustração, mas, antes, inclusive, da racionalidade em si própria, que considerava encontrar-se sob ameaça.

No ano de 1783 Kant escreveu os Prolegômenos para toda metafísica futura que se apresente como ciência, em resposta às críticas recebidas pelo seu primeiro esforço. No ano seguinte, publicou a Ideia de uma História Universal de um Ponto de Vista Cosmopolita e, em dezembro do mesmo ano, O que é o esclarecimento?, que representa uma clara defesa da sua versão do movimento ilustrado. Em 1785 foi a vez da Fundamentação da Metafísica dos Costumes, que começou como uma espécie de "vingança" contra um dos seus críticos (KUEHN apud GUYER 2006, p. 645) e acabou como uma defesa da moral baseada a priori nos conceitos puros do entendimento e não na ordem social estabelecida; no ano seguinte apareceram os Primeiros princípios metafísicos da ciência natural (1786) como resposta a um debate com Johann Schulz e J. A. Ulrich, quem havia de fato incorporado a Crítica no seu próprio trabalho.

O ano de 1786 viu também a morte de Frederico II, e a ascensão ao trono do seu sobrinho, Federico Guilherme II, que significou um duro golpe à liberdade intelectual reinante. Frederico II havia sido um grande defensor dos "racionalistas secularizantes" que se concentravam em Berlim (ZAMMITO 1992 , p. 11), mas que agora deviam lidar com as diretivas tradicionalistas do novo monarca (STANTON FORD 1910). O fim da liberalidade religiosa imperante coincidiu com o desenvolvimento da disputa sobre o panteísmo, datada ao redor dos anos de 1785-1789, que envolveu principalmente Lessing e Jacobi. O próprio Kant participou dessa disputa com o seu ensaio Was heißt: sich im Denken orientieren?, de 1786, destinado a refutar qualquer possibilidade de interpretar as teses da Crítica como apoio ao spinozismo (ZAMMITO 1992, p. 12). No mesmo ano de 1785, F. H. Jacobi publicou o Prometeu, de J. W. Goethe, mais um dos livros louvados pelos "detratores" da Ilustração. Em 1787, dentro do mesmo marco, J. G. von Herder publicou o segundo volume das suas Ideias: Gott: eine Gespräche. O ano de 1787 também marca o início da preparação da Crítica do juízo, cujo texto revisado seria publicado em 1790, que se ocupa, não por acaso, com o juízo reflexionante, e a finalização da escrita da Crítica da razão prática, que Kant publicaria um ano depois, em 1788.

Em definitiva, as diferenças entre as duas edições da Crítica sugerem que é impossível compreender o projeto teórico separado do projeto político de todos estes filósofos, e que uma parte importante do debate político foi disputado através da teoria. Isso não nos surpreenderia, se não fosse pelos colossais esforços dispensados (por Kant, mas também pelos seus intérpretes) em separar a teoria da prática, na medida em que a objetividade da ciência 
kantiana faz parte do argumento político do projeto da Ilustração que resultou vitorioso, pelo menos temporariamente.

Mas para compreender que a discrepância entre estas duas "imaginações" não significa necessariamente uma oposição entre racionalidade e irracionalidade ou entre modernidade e não modernidade, é preciso pensar a Ilustração como um movimento mais amplo do que a "virada" Crítica kantiana, que envolve diferentes visões da missão da Aufklärung e das ferramentas adequadas para o seu cumprimento. Os filósofos populares em todas as suas formas, e inclusive na sua forma de Sturm und Drang e de schöne Wissenschaften, não se opunham à ideia da Aufklärung. Discordavam sim da opinião de que os objetivos libertários e pedagógicos dessa Auklärung pudessem ser alcançados através da filosofia sistemática ou da Schülphilosophie (ZAMMITO 2002, p. 37) que Kant iria defender depois da virada Crítica. O Sturm und Drang mantinha o espírito daquele pietismo originalmente ensinado por Christian Thomasius, na qual a Ilustração era entendida como um filosofar no dia a dia, utilizando palavras compreensíveis, belas e agradáveis que permitissem satisfazer o seu ideal pedagógico. Este objetivo, que também estava presente na filosofia de Kant deveria, e só podia ser realizado na comunidade real, através da força da história (ZERMEÑO PADILLA 2010, p. 105), mais do que mediante o estabelecimento apriorístico de um imperativo categórico.

A reivindicação do Sturm und Drang em favor de uma imaginação pessoal, individual e genial constitui um posicionamento em favor da imaginação criativa, ou Dichtungskraft, diferenciada da imaginação (Einbildungskraft) como percepção geral da realidade. Simultaneamente, significa também uma vontade de aprofundar a radicalidade da Aufklärung para além da razão e da própria individualidade, que em todo momento se descobre tão urgente quanto irrealizável. A individualidade deixa de ser pensada como uma totalidade racional e visível de sentido, para passar a ser uma sensação corporal, mas invisível, que redefine o conceito de imaginação como a capacidade de sentir o mundo de maneira particular e muitas vezes extrema, inclusive insuportável, como bem mostra a trajetória do jovem Werther.

O debate sobre o conhecimento, isto é, o debate sobre as capacidades da alma, parecia polarizar-se cada vez mais entre uma concepção racionalista e outra sentimentalista. É por esse motivo que a Crítica, na sua segunda versão, privilegiava a função e o poder do entendimento antes que o da imaginação, acentuando o seu combate à chamada metafísica dogmática e também ao panteísmo. Essa tendência progressiva em direção ao racionalismo e à postulação de um dualismo poderia ser lida como uma defesa do entendimento que, com o seu crescimento desmedido, acabou desmerecendo a imaginação mais do que pretendia no intuito de não sucumbir ao império absoluto da poiesis imaginativa, agora identificada com a irracionalidade. Heidegger toca diretamente na ferida quando pergunta: "Através da redução das faculdades de conhecimento de um ser finito à imaginação, não ficaria todo conhecimento reduzido ao puramente imaginário [zur bloßen Einbildung herabgesetzt]?" (HEIDEGGER 1991, p. 138). 


\section{Referências bibliográficas}

ALEXANDER, W. M. Johann Georg Hamann: Metacritic of Kant. Journal of the History of Ideas, v. 27, n. 1, p. 137-144, 1966.

BALLARD, K. E. Leibniz's Theory of Space and Time. Journal of the History of Ideas, v. 21, n. 1, p. 49-65, 1960.

BAMBACH, C. Heidegger, Dilthey and the crisis of historicism. Cambridge: Cambridge University Press, 1995.

BAUMGARTEN, A. G. Esthétique. Méditations philosophiques sur quelques sujets se rapportan à l'essence du poème. Métaphysique. Paris: L'Herne, 1988.

BERLIN, I. The roots of romanticism. Princeton: Princeton University Press, 1999.

CALINGER, R. The newtonian-wolffian controversy, 1740-1759. Journal of the History of Ideas, v. 30, n. 3, p. 319-330, 1969.

Kant The and Newtonian Science: the precritical period. Isis, v. 70, n. 3, p. 348-362, 1979.

CALKINS, M. Kant's Conception of the Leibniz Space and Time Doctrine. The philosophical review, v. 6, n. 4, p. 356-369, 1897.

CASSIRER, E. Kant und das Problem der Metaphysik. Bemerkungen zu Martin Heideggers Kantinterpretation. Kant-Studien, v. 36, 1931.

GOETHE, J. W. The Poems of Goethe translated in the original metres. London: Bowring, 1998.

GUYER, P. The Cambridge companion to Kant and modern philosophy. Cambridge: Cambridge University Press, 2006.

HEIDEGGER, M. Kant and the Problem of Metaphysics. Indiana: Indiana University press, 1962.

Gesamtausgabe Band 3. Kant und das Problem der Metaphysik. Frankfurt am Main: Vittorio Klostermann, 1991.

HERDER, J. G. Philosophical writings. Cambridge: Cambridge University Press, 2002.

HILlEBRAND, K. Herder. I. The North American Review, v. 115, n. 236, p. $104-138,1872$.

KANT, I. Anthropologie in pragmatischer Hinsicht. Leipzig: Immanuel Müller, 1833.

Kritik der reinen Vernunft. Hamburg: Felix Meiner, 1956.

Lectures on Metaphysics. Cambridge: Cambridge University Press, 1997.

Critica da razão pura. Lisboa: Calouste Gulbenkian, 2001. 
- Anthropology History and Education. Cambridge: Cambridge University Press, 2006.

KUEHN, M. Kant: A Biography. Cambridge: Cambridge University Press, 2001.

LEIBNIZ, G. New Essays on Human Understanding. Jonathan Bennet, 2010. MAKKREEL, R. A. Imagination and interpretation in Kant: the Hermeneutical Import of the Critique of Judgment. Chicago: The University of Chicago Press, 1990.

MENDELSSOHN, M. Saemmtliche Werke. Band VI. [s.I.] Paul Burianschen Buchhandlung, 1819.

RUPERT HALL, A. Philosophers at war: the quarrel between Newton and Leibniz. Cambridge: Cambridge University Press, 2002.

SCHÖNFELD, M. The philosophy of the young Kant: the precritical project. Oxford: Oxford University Press, 2000.

SHEROVER, C. Heidegger, Kant and time. Bloomington: Indiana University press, 1971.

SIKKA, S. Herder's critique of pure reason. The review of metaphysics, v. 61, n. 1, p. 31-50, 2007.

STANTON FORD, G. Wollner and the religious edict of 1788, II. The American historical review, v. 15, n. 3, p. 509-525, 1910.

92

WEATHERSTON, M. Heidegger's Interpretation of Kant: categories, Imagination, and Temporality. [s.I.] Palgrave Macmillan, 2002.

ZAMMITO, J. The Genesis of Kants Critique of Judgment. Chicago: The University of Chicago Press, 1992.

. Kant, Herder and the birth of anthropology. Chicago: The University of Chicago press, 2002.

ZERMEÑO PADILLA, G. La cultura moderna de la historia: una aproximación teórica. México: El colegio de México, 2010. 